\title{
Simultaneous Occurrence of Quadruple Lewis Acid-Base Interactions between Selenium Atoms in Selenocarbonyl Dimers
}

\author{
Gabriel J. Buralli, ${ }^{[a, b]}$ Darío J. R. Duarte, ${ }^{*[a, b]}$ Nélida M. Peruchena, ${ }^{*[a, b]}$ and Ibon Alkorta ${ }^{[c]}$
}

High-level quantum chemical calculations are performed to investigate $\mathrm{C}=\mathrm{Se}$... $\mathrm{Se}=\mathrm{C}$ interactions. Bounded structures are found with binding energies between -4 and $-7 \mathrm{~kJ} \mathrm{~mol}^{-1}$. An energy decomposition analysis shows that dispersion is the more attractive term, and in all cases save one, the electrostatic interaction is attractive despite each selenium atom having a positive $\sigma$-hole at the extension of the $\mathrm{C}=\mathrm{Se}$ bond. The topological analysis of the molecular electrostatic potential and $L(\mathbf{r})=-\nabla^{2} \rho(\mathbf{r})$ function, and natural bond orbital analysis reveal that these particular Se...Se contacts can be considered to be quadruple Lewis acid-base interactions.

\section{Introduction}

Chalcogen bonds (YBs) are noncovalent interactions between a chalcogen atom $(\mathrm{O}, \mathrm{S}, \mathrm{Se}, \mathrm{Te})$ and a Lewis base. Several types of these interactions have been reported. Structural, topological, and energetic characteristics are very similar to those of interactions categorized as $\sigma$-hole bonding. ${ }^{[1-6]}$

A recent search of the Cambridge Structural Database (CSD) showed that S...S contacts between cysteine fragments $\left(\mathrm{RCH}_{2} \mathrm{SH}\right)$ prefer parallel orientations. Calculations at the $\operatorname{CCSD}(\mathrm{T}) / \mathrm{CBS}$ level of theory show that this geometry has an interaction energy of $-7.5 \mathrm{~kJ} \mathrm{~mol}^{-1} \cdot{ }^{[4]}$ Moreover, selenium is an essential micronutrient that is incorporated as selenocysteine at the active sites of a wide range of proteins. ${ }^{[7]}$ Thus, the control of Se...Se contacts could be of fundamental importance to human health.

A detailed analysis of several YBs reveals that the hybridization of the chalcogen atom can play an important role in their strength. When the chalcogen atom has $\mathrm{sp}^{3}$ hybridization, the $Y B$ is mainly governed by electrostatic and exchange components with less contribution from the dispersive component. ${ }^{[2,5,8-10]}$ When the chalcogen atom has $\mathrm{sp}^{2}$ hybridization,

[a] G. J. Buralli, Dr. D. J. R. Duarte, Prof. N. M. Peruchena Laboratorio de Estructura Molecular y Propiedades Área de Química Física, Departamento de Química Facultad de Ciencias Exactas y Naturales y Agrimensura Universidad Nacional del Nordeste

Avenida Libertad 5460 (3400) Corrientes (Argentina) E-mail:djr_duarte@hotmail.com

[b] G. J. Buralli, Dr. D. J. R. Duarte, Prof. N. M. Peruchena IQUIBA-NEA (UNNE-CONICET)

Avenida Libertad 5460 (3400) Corrientes (Argentina) E-mail:arabeshai@yahoo.com.ar

[c] Prof. I. Alkorta

Instituto de Química Médica, CSIC Juan de la Cierva, 3, 28006 Madrid (Spain)

Supporting Information and the ORCID identification number(s) for the

(D) author(s) of this article can be found under: https://doi.org/10.1002/cphc.201700682. dispersive forces can dominate over electrostatic forces. ${ }^{[1,11]}$ In other cases, such as $\mathrm{F}_{2} \mathrm{CSe} \cdots \mathrm{NH}_{3}, \mathrm{OCS} \cdots \mathrm{Cl}^{-}, \mathrm{SCS} \cdots \mathrm{Cl}^{-}$, and $\mathrm{F}_{2} \mathrm{CS} \ldots \mathrm{Cl}^{-}, \mathrm{YBs}$ are dominated by electrostatic forces and electron charge transfer from the lone pairs of the Lewis base to an antibonding orbital of the Lewis acid. ${ }^{[1,12]}$ The weak molecular interactions of $\mathrm{O}=\mathrm{C}=\mathrm{S}, \mathrm{S}=\mathrm{C}=\mathrm{S}, \mathrm{F}_{2} \mathrm{C}=\mathrm{S}$, and $\mathrm{Cl}_{2} \mathrm{C}=\mathrm{S}$ with singlet carbene have studied by Zhao et al., who used a fragment-based energy decomposition analysis (EDA) for the interaction energies to show that that the electrostatic component is the main stabilizing factor in these complexes. ${ }^{[13]}$

Guo et al. ${ }^{[11,12]}$ showed through analysis of the molecular electrostatic potential (MEP) that the selenium atom of the $\mathrm{F}_{2} \mathrm{C}=\mathrm{Se}$ molecule can act as Lewis acid and Lewis base. They found that the Se atom has an $\sigma$-hole $\left(77.9 \mathrm{~kJ} \mathrm{~mol}^{-1}\right)$ centered around the extension of the $\mathrm{C}=\mathrm{Se}$ bond and two regions of negative electrostatic potential $\left(-40.8 \mathrm{~kJ} \mathrm{~mol}^{-1}\right)$ on the two sides of the $\mathrm{C}=\mathrm{Se}$ bond in the molecular plane, corresponding to the lone pairs on the Se atom. According to these authors, $\mathrm{F}_{2} \mathrm{C}=\mathrm{Se}$ can form $\mathrm{YB}$ complexes through the $\sigma$-hole with $\mathrm{N}_{2}$, $\mathrm{NH}_{3}, \mathrm{NCH}, \mathrm{NHCH}_{2}, \mathrm{NMe}_{3}$, and $\mathrm{NCLi}$, and can act as a Lewis base through the MEP minima and form hydrogen bonds with $\mathrm{HX}$ $(\mathrm{X}=\mathrm{F}, \mathrm{Cl}, \mathrm{OH}, \mathrm{CN})$ molecules, halogen bonds with dihalogen molecules ( $\mathrm{BrCl}, \mathrm{ClF}$, and $\mathrm{BrF})$, and dative bonds with $\mathrm{BeH}_{2}$ and $\mathrm{BH}_{3}{ }^{[11,12]}$

On the other hand, recently chalcogen...chalcogen contacts ${ }^{[14]}$ have been divided into two categories, depending on their geometry: types I and II (see Scheme 1), like halogen...halogen contacts. ${ }^{[15]}$ According to an extensive crystallographic and theoretical analysis performed by Shukla and Chopra, the $\mathrm{C}=\mathrm{S} \cdots \mathrm{S}=\mathrm{C}$ contacts are of dispersive nature with electrostatics contributing to the destabilization in some cases. ${ }^{[14]}$ Even though more than $70 \%$ of structures have type I S...S contacts, there are some indications of linear $\mathrm{C}=\mathrm{S} . . . \mathrm{S}=\mathrm{C}$ contacts that were not classified (see Figure $3 \mathrm{f}$ in ref. [14]).

Most of the characteristics of YBs are understood in terms of the $\sigma$-hole concept. However, in several examples in the litera- 


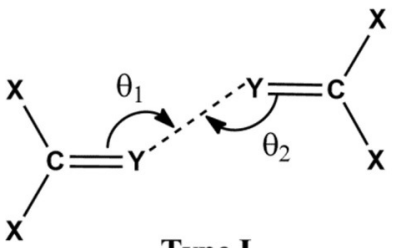

Type I

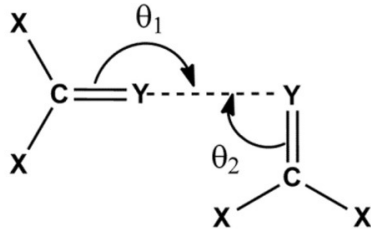

Type II
Scheme 1. Schematic representation of chalcogen...chalcogen contacts. Type I: $\theta_{1} \cong \theta_{2}$ and type II, $\theta_{1} \cong 180^{\circ}, \theta_{2} \cong 90^{\circ}$.

ture it is shown that the $\sigma$-hole concept fails. ${ }^{[16-18]}$ Recently, many of the characteristics of some molecular interactions, such as beryllium bond, ${ }^{[19]}$ pnicogen bonds, ${ }^{[20,21]}$ chalcogen bond $^{[3,6]}$ halogen bond ${ }^{[22,23]}$ and $\mathrm{O} \cdots \mathrm{X}(\mathrm{X}=\mathrm{O}, \mathrm{N})$ interactions, $^{[24]}$ have been explained through the hole-lump concept, ${ }^{[25,26]}$ extracted from the topology of the $L(\mathbf{r})=-\nabla^{2} \rho(\mathbf{r})$ function. According to this concept, a molecular interaction involving a Lewis acid-base interaction is due to a lump-hole interaction, whereby the full quantum electrostatic potential is used. ${ }^{[20]}$

The electron density and MEP ${ }^{[27-29]}$ are observable properties of the system that can be experimentally and theoretically studied. In the framework of halogen bonds, we have used the hole-lump concept to explain the simultaneous occurrence of Lewis acid-base interactions in halogen...halogen contacts of types ${ }^{[30]}$ and ${ }^{[I .}{ }^{[23]}$ According to the MEP, it appears that the $\mathrm{R}_{2} \mathrm{C}=\mathrm{Se}$ molecules cannot form dimers or binary complexes by facing each other through positive $\sigma$-holes. ${ }^{[11,12]}$ However, in the present work we found stable linear $\mathrm{C}=\mathrm{Se}$... $\mathrm{Se}=\mathrm{C}$ contacts in which each Se atom simultaneously acts as Lewis acid and base; a similar situation has been already been described for pnicogen-bonded dimers. ${ }^{[31-33]}$ This study points out the importance of molecular interactions in which selenocarbonyl groups can participate, and may be useful for recognizing attractive Se...Se contacts in crystal structures and biomolecules.

\section{Computational Details}

The geometries of monomers and complexes were optimized by second-order Møller-Plesset perturbation theory (MP2) ${ }^{[34]}$ with the aug-cc-pVTZ basis set. For the Se atom the aug-cc-pVTZ-PP basis set was used. Frequency calculations were performed at the same level of theory. All optimization, harmonic vibrational frequency, and single-point energy calculations at the HF, MP2, and $\operatorname{CCSD}(\mathrm{T})$ levels of theory were performed with the Gaussian 09 program package..$^{[35]}$

The interaction energy was calculated by using the extrapolation scheme proposed by Helgaker et al. [Eqs. (1)-(5) $]^{[36,37]}$ following the recommendations of Hobza et al. [Eq. (6)]:[38]

$$
\begin{aligned}
& E_{\mathrm{X}}^{\mathrm{HF}}=E_{\mathrm{CBS}}^{\mathrm{HF}}+B e^{-X \alpha} \\
& E_{\mathrm{CBS}}^{\mathrm{HF}}=\frac{E_{4}^{\mathrm{HF}} e^{4 \alpha}-E_{3}^{\mathrm{HF}} e^{3 \alpha}}{e^{4 \alpha}-e^{3 \alpha}} \\
& E_{\mathrm{coor}, X}^{\mathrm{MP} 2}=E_{X}^{\mathrm{MP} 2}-E_{X}^{\mathrm{HF}} \\
& E_{\mathrm{coor}, \lim }^{\mathrm{MP} 2}=\frac{4^{3} E_{\mathrm{coor}, 4}^{\mathrm{MP} 2}-3^{3} E_{\mathrm{coor}, 3}^{\mathrm{MP} 2}}{4^{3}-3^{3}}
\end{aligned}
$$

$E_{\mathrm{CBS}}^{\mathrm{MP2}}=E_{\mathrm{CBS}}^{\mathrm{HF}}+E_{\text {coor.lim }}^{\mathrm{MP2}}$

$E_{\mathrm{CBS}}^{\mathrm{CCS}(\mathrm{T})}=E_{\mathrm{CBS}}^{\mathrm{MP2}}+\left(E_{3}^{\mathrm{CCSD}(\mathrm{T}) 2}-E_{3}^{\mathrm{MP2}}\right)$

where $\alpha=1.54$ and $X$ is the cardinal number of the employed basis set: 3 for aug-cc-pVTZ (aug-cc-pVTZ-PP for Se) and 4 for aug-ccpVQZ (aug-cc-pVQZ-PP for Se), and CBS denotes complete basis set.

All complexes were optimized with $C_{2 v}$ or $D_{2 d}$ symmetry as appropriate. If the symmetry is not imposed, type I or II Se...Se contacts are obtained with similar interaction energies (e.g., for $\mathrm{H}_{2} \mathrm{CSe} \cdots \mathrm{SeCH}_{2}$ complexes: type I: $-4.2 \mathrm{~kJ} \mathrm{~mol}^{-1}$, type II: $-6.5 \mathrm{~kJ} \mathrm{~mol}^{-1}$, and type III: $-5.2 \mathrm{~kJ} \mathrm{~mol}^{-1}$, calculated at the $\operatorname{CCSD}(\mathrm{T}) / \mathrm{CBS}$ level of theory).

The interaction energies $E_{\text {int }}$ were decomposed by following the localized molecular orbital energy decomposition analysis $(\text { LMOEDA })^{[39]}$ formalism according to Equation (7):

$E_{\text {int }}=E_{\text {elect }}+E_{\text {ex-rep }}+E_{\mathrm{pol}}+E_{\text {disp }}$

where $E_{\text {elect }}$ is the electrostatic term describing the classical Coulomb interaction, $E_{\text {ex-rep }}$ the exchange-repulsion component resulting from the Pauli exclusion principle, and $E_{\mathrm{pol}}$ and $E_{\text {disp }}$ are polarization and dispersion terms, respectively. These calculations were carried out with the quantum chemistry program package GAMESS (version 2013-R1) ${ }^{[40]}$ at the same level of theory as the optimization.

The intermolecular distributions of the electron density and $L(\mathbf{r})=$ $-\nabla^{2} \rho(\mathbf{r})$ function were studied in the framework of the quantum theory of atoms in molecules (QTAIM) ${ }^{[25,26,41]}$ with the AIMAll program. ${ }^{[42]}$ The molecular electrostatic potential $V(\mathbf{r})$ and electric field lines were calculated with the Multiwfn program. ${ }^{[43]}$ The electrondensity shift map was generated as the difference between the electron density of the complex and the sum of the electron densities of the isolated monomers.

To better understand the charge transfer between the monomers, a natural bond orbital (NBO) analysis was carried out at the HF/ aug-cc-pVTZ level of theory with MP2/aug-cc-pVTZ geometries.

The maps of the MEP, the envelope of $L(r)$ function and electrondensity shifts, and contour lines of the electric field were drawn with JMOL, ${ }^{[44]}$ AIMAll, $^{[42]}$ and Multiwfn ${ }^{[43]}$ programs, respectively.

\section{Results and Discussion}

The isolated $\mathrm{X}_{2} \mathrm{C}=\mathrm{Se}\left(\mathrm{X}=\mathrm{H}, \mathrm{F}, \mathrm{Cl}, \mathrm{Br}, \mathrm{OH}, \mathrm{CH}_{3}\right)$ molecules show $C_{2 v}$ symmetry. The MEP of these molecules shows a $\sigma$-hole in the extension of the $\mathrm{C}=\mathrm{Se}$ bond (Figure 1). The electrostatic potentials at the $\sigma$-hole range between 84.0 and $3.4 \mathrm{~kJ} \mathrm{~mol}^{-1}$ for $\mathrm{F}_{2} \mathrm{CSe}$ and $\left(\mathrm{CH}_{3}\right)_{2} \mathrm{CSe}$, respectively (see Table $\mathrm{S} 1$ of the Supporting Information).

Selected geometric parameters calculated at the same level of optimization and the interaction energies of $\mathrm{X}_{2} \mathrm{C}=\mathrm{Se} \cdot . \mathrm{Se}=$ $\mathrm{CY}_{2}$ complexes are reported in Table 1. The interaction energies are similar to those of the $\mathrm{YB}$ complexes $\mathrm{O}=\mathrm{C}=\mathrm{S} \cdots \mathrm{CH}_{2}$ $\left(-7.9 \mathrm{~kJ} \mathrm{~mol}^{-1}\right), \quad \mathrm{S}=\mathrm{C}=\mathrm{S} \cdots \mathrm{CH}_{2} \quad\left(-6.8 \mathrm{~kJ} \mathrm{~mol}^{-1}\right), \quad \mathrm{F}_{2} \mathrm{C}=\mathrm{S} \cdots \mathrm{CH}_{2}$ $\left(-5.4 \mathrm{~kJ} \mathrm{~mol}^{-1}\right)$, and $\mathrm{Cl}_{2} \mathrm{C}=\mathrm{S} \cdots \mathrm{CH}_{2}\left(-5.4 \mathrm{~kJ} \mathrm{~mol}^{-1}\right)$ studied by Zhao et al . ${ }^{[13]}$ 


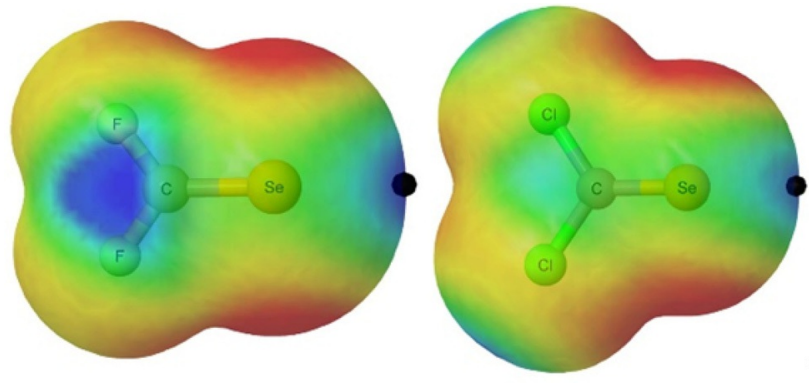

Figure 1. Electrostatic potential on the 0.001 au electron-density isosurface. The color code is red $=-26.2 \mathrm{~kJ} \mathrm{~mol}^{-1}$ and blue $=+78.8 \mathrm{~kJ} \mathrm{~mol}^{-1}$. The location of the $\sigma$-hole is indicated by a black dot.

Table 1. Selected geometric parameters and interaction energies.

\begin{tabular}{|c|c|c|c|}
\hline Complex & $d(\mathrm{Se} \cdots \mathrm{Se})^{[\mathrm{a}]}$ & $\Delta d(\mathrm{Se} \cdots \mathrm{Se})^{[\mathrm{b}]}$ & $E_{\mathrm{int}}^{[\mathrm{c}]}$ \\
\hline $\mathrm{H}_{2} \mathrm{CSe} \cdots \mathrm{SeCH}_{2}$ & 3.385 & 0.515 & -5.1 \\
\hline $\mathrm{F}_{2} \mathrm{CSe} \cdots \mathrm{SeCH}_{2}$ & 3.415 & 0.485 & -5.2 \\
\hline $\mathrm{Cl}_{2} \mathrm{CSe} \cdot \cdots \mathrm{SeCH}_{2}$ & 3.414 & 0.486 & -6.5 \\
\hline $\mathrm{Br}_{2} \mathrm{CSe} \cdot . . \mathrm{SeCH}_{2}$ & 3.393 & 0.507 & -7.1 \\
\hline$(\mathrm{OH})_{2} \mathrm{CSe} \cdots \mathrm{SeCH}_{2}$ & 3.411 & 0.489 & -4.1 \\
\hline$\left(\mathrm{CH}_{3}\right)_{2} \mathrm{CSe} \cdots \mathrm{SeCH}_{2}$ & 3.432 & 0.468 & -5.7 \\
\hline $\mathrm{F}_{2} \mathrm{CSe} \cdots \mathrm{SeCF}_{2}$ & 3.508 & 0.392 & -4.3 \\
\hline $\mathrm{Cl}_{2} \mathrm{CSe} \cdots \mathrm{SeCCl}_{2}$ & 3.409 & 0.491 & -6.2 \\
\hline $\mathrm{Br}_{2} \mathrm{CSe} \cdots \mathrm{SeCBr}_{2}$ & 3.315 & 0.585 & -7.3 \\
\hline$(\mathrm{OH})_{2} \mathrm{CSe} \cdots \mathrm{SeC}(\mathrm{OH})_{2}$ & 3.491 & 0.409 & -5.2 \\
\hline$\left(\mathrm{CH}_{3}\right)_{2} \mathrm{CSe} \cdots \mathrm{SeC}\left(\mathrm{CH}_{3}\right)_{2}$ & 3.436 & 0.464 & -5.2 \\
\hline
\end{tabular}

[a] $d(\mathrm{Se}$...Se) $[\AA]$ : intermolecular distances. [b] $\Delta d(\mathrm{Se}$...Se) $[\AA]$ : difference between the sum of the van der Waals radii ${ }^{[45]}$ of the Se atoms and intermolecular distances in the complex. $E_{\mathrm{lnt}}\left[\mathrm{kJ} \mathrm{mol}^{-1}\right]$ : interaction energies calculated at the $\operatorname{CCSD}(\mathrm{T}) / \mathrm{CBS}$ level of theory.

With the aim of discussing the electronic effects of the substituents on the stabilization of these complexes, we replaced the $\mathrm{H}$ atoms by various groups of different electron-withdrawing/donating capacity. When the $\mathrm{H}$ atoms are replaced by halogen atoms, the interaction energies for heterodimer complexes are ranked according to the size of the substituent: $\mathrm{H}<$ $\mathrm{F}<\mathrm{Cl}<\mathrm{Br}$. Thus, it appears that the electronic effect of a substituent is less relevant than its size. However, for homodimer complexes, the interaction energies follow the order $\mathrm{F}<\mathrm{H}<$ $\mathrm{Cl}<\mathrm{Br}$. When we compare the heterodimers with the corresponding homodimers, differences are observed only for $F$ and $\mathrm{OH}$ substituents, whereas for the rest of the complexes no significant differences were observed.

All systems were optimized with $C_{2 v}$ or $D_{2 d}$ symmetry as appropriate, with the two planes formed by the monomers perpendicular to each other. In most of the complexes studied here small imaginary frequencies $\left(<20 \mathrm{i} \mathrm{cm}^{-1}\right)$ are observed, except for the $\mathrm{H}_{2} \mathrm{C}=\mathrm{Se} \cdots \mathrm{Se}=\mathrm{CH}_{2}$ and $\left(\mathrm{CH}_{3}\right)_{2} \mathrm{C}=\mathrm{Se} \cdot \mathrm{Se}=\mathrm{C}\left(\mathrm{CH}_{3}\right)_{2}$ complexes, which have no imaginary frequencies. In any case, the systems considered have bounding energies and their dissociation profiles, such as that of the $\mathrm{F}_{2} \mathrm{C}=\mathrm{Se} \cdot . \cdot \mathrm{Se}=\mathrm{CF}_{2}$ complex shown in Figure 2, show a relatively deep well $\left(-8.3 \mathrm{~kJ} \mathrm{~mol}^{-1}\right.$ calculated at the MP2/aug-cc-pVTZ level of theory). Similar small imaginary frequencies have been reported for other re-

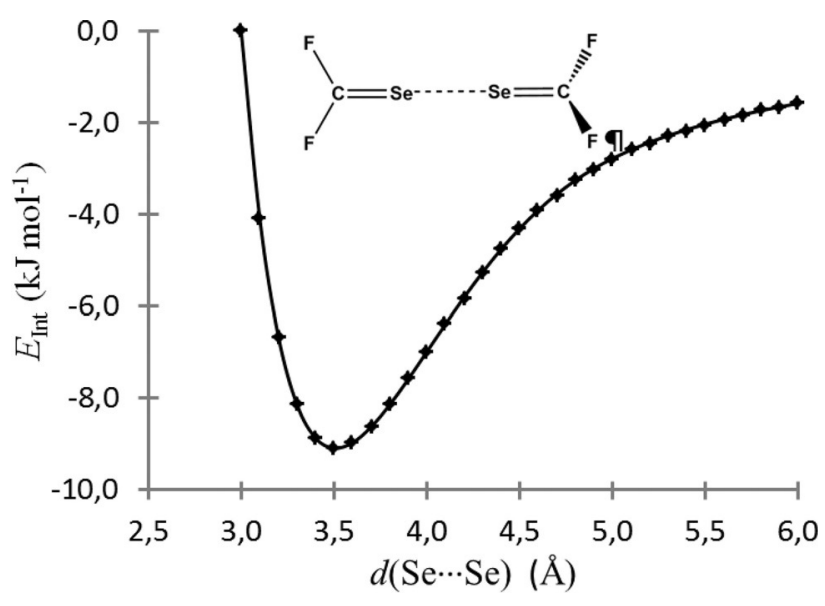

Figure 2. Minimum-energy path for the approach of Se atoms of $\mathrm{F}_{2} \mathrm{C}=$ $\mathrm{Se} \cdot . \mathrm{Se}=\mathrm{CF}_{2}$ in linear $\mathrm{C}=\mathrm{Se} \cdots \mathrm{Se}=\mathrm{C}$ conformation, calculated at the MP2/augcc-pVTZ level of theory.

lated systems such as $\mathrm{R}_{2} \mathrm{C}=\mathrm{S} \cdots \mathrm{Cl}^{-}(\mathrm{R}=\mathrm{H}, \mathrm{F})^{[1]}$ and $\mathrm{R}_{2} \mathrm{C}=\mathrm{S} \ldots \mathrm{CH}_{2}$ $(\mathrm{R}=\mathrm{F}, \mathrm{Cl})^{[13]}$ complexes.

These Se...Se interactions are of stabilizing nature $\left(E_{\text {int }}<0\right)$ and range from -4.1 to $-7.3 \mathrm{~kJ} \mathrm{~mol}^{-1}$ (see Table 1). These results are in partial agreement with those reported for S...S interactions by Shukla and Chopra, ${ }^{[14]}$ according to whom the $\mathrm{C}=\mathrm{S} \cdots \mathrm{S}=\mathrm{C}$ contacts are stabilizing in some molecular pairs but a consequence of crystal packing in others. In the complexes studied by Shukla and Chopra, the binding energies ranged from -6.7 to $+3.7 \mathrm{~kJ} \mathrm{~mol}^{-1}$.

The $\mathrm{C}=\mathrm{Se} \cdot \cdots \mathrm{Se}=\mathrm{C}$ contacts have intermolecular Se...Se distances of about $3.4 \AA$, which is shorter than the sum of the van der Waals radii $(3.9 \AA)^{[45]}[\Delta d(\mathrm{Se} \ldots \mathrm{Se})>0 \AA]$. The two planes that contain the monomers are perpendiculars to each other. This is essentially different to most S...S contacts found by Shukla and Chopra. ${ }^{[14]}$ On the basis of this crystallographic study by Shukla et al. and the intermolecular Se...Se distances and symmetries of complexes reported herein, it appears that there are three types of chalcogen...chalcogen contacts: type I $\left(\theta_{1} \approx \theta_{2} \approx 140-160^{\circ}\right)$, type II $\left(\theta_{1} \approx 180^{\circ}\right.$ and $\left.\theta_{2} \approx 90^{\circ}\right)$, and type III $\left(\theta_{1} \approx \theta_{2} \approx 180^{\circ}\right)$. However, it appears that only type III $\mathrm{H}_{2} \mathrm{C}=$ $\mathrm{S}$... $\mathrm{S}=\mathrm{CH}_{2}$ contacts have been found in crystallographic studies (see Figure $7 \mathrm{a}$ in ref. [14]).

Energy decomposition analysis (Table 2) reveals interesting features of $\mathrm{C}=\mathrm{Se}$... $\mathrm{Se}=\mathrm{C}$ interactions. In general, the stabilizing electrostatic components $E_{\text {elect }}$ and $E_{\mathrm{pol}}$ are the least important terms, whereas in all complexes the most important stabilization term is the dispersive component. Moreover, the electrostatic components $E_{\text {elect }}$ and $E_{\mathrm{pol}}$ are attractive (except for $\mathrm{F}_{2} \mathrm{CSe} . . . \mathrm{SeCF}_{2}$, in which $E_{\text {elect }}<0$ ), although the selenium atoms have a positive $\sigma$-hole at the extension of $\mathrm{C}=\mathrm{Se}$ bond. Similar observations have been made for $\mathrm{Y} \cdots \mathrm{Y}(\mathrm{Y}=\mathrm{O}, \mathrm{S}, \mathrm{Se}, \mathrm{Te})$ contacts, in which the most important stabilization term is the dispersion. ${ }^{[46]}$ However, these observations are essentially different from those made for the linear $\mathrm{F}-\mathrm{Br} \cdots \mathrm{Br}-\mathrm{F}$ system, ${ }^{[23]}$ in which the two interacting regions also show positive values of the electrostatic potential and the electrostatic component is always repulsive. 


\begin{tabular}{|c|c|c|c|c|c|}
\hline Complex & $E_{\text {elect }}$ & $E_{\text {ex-rep }}$ & $E_{\mathrm{pol}}$ & $E_{\text {disp }}$ & $E_{\text {int }}$ \\
\hline $\mathrm{H}_{2} \mathrm{CSe} \ldots . \mathrm{SeCH}_{2}$ & -5.9 & 20.4 & -4.9 & -16.9 & -7.2 \\
\hline $\mathrm{F}_{2} \mathrm{CSe} \cdots \mathrm{SeCH}_{2}$ & -3.7 & 16.4 & -4.3 & -15.1 & -6.8 \\
\hline $\mathrm{Cl}_{2} \mathrm{CSe} \cdots \mathrm{SeCH}_{2}$ & -4.3 & 17.1 & -4.6 & -16.7 & -8.4 \\
\hline $\mathrm{Br}_{2} \mathrm{CSe} \cdots \mathrm{SeCH}_{2}$ & -4.8 & 18.5 & -4.9 & -17.6 & -8.8 \\
\hline$(\mathrm{OH})_{2} \mathrm{CSe} \cdots \mathrm{SeCH}_{2}$ & -2.5 & 17.2 & -4.6 & -17.0 & -6.9 \\
\hline$\left(\mathrm{CH}_{3}\right)_{2} \mathrm{CSe} \cdots \mathrm{SeCH}_{2}$ & -4.1 & 17.6 & -4.2 & -17.3 & -7.9 \\
\hline $\mathrm{F}_{2} \mathrm{CSe}_{\cdots} \cdot \mathrm{SeCF}_{2}$ & 0.5 & 10.3 & -3.1 & -13.1 & -5.3 \\
\hline $\mathrm{Cl}_{2} \mathrm{CSe} \cdot \cdots \mathrm{SeCCl}_{2}$ & -2.2 & 16.0 & -4.5 & -17.5 & -8.3 \\
\hline $\mathrm{Br}_{2} \mathrm{CSe}$...SeCBr ${ }_{2}$ & -3.8 & 22.3 & -6.2 & -21.1 & -8.9 \\
\hline$(\mathrm{OH})_{2} \mathrm{CSe} \cdots \mathrm{SeC}(\mathrm{OH})_{2}$ & -0.5 & 12.3 & -2.7 & -15.3 & -6.5 \\
\hline$\left(\mathrm{CH}_{3}\right)_{2} \mathrm{CSe} \cdots \mathrm{SeC}\left(\mathrm{CH}_{3}\right)_{2}$ & -0.3 & 13.5 & -3.1 & -17.4 & -7.3 \\
\hline
\end{tabular}

[a] All values in $\mathrm{kJ} \mathrm{mol}^{-1}$

Table 3 lists the values of the local topological properties at the Se...Se bond critical points (BCPS) obtained from QTAIM. Figure $\mathrm{S} 1$ shows the presence of a $\mathrm{BCP}$ and a corresponding bond path that links the interacting Se atoms, and thus con-

\begin{tabular}{|c|c|c|c|}
\hline Complex & $\rho\left(\mathbf{r}_{\mathrm{b}}\right)$ & $\nabla^{2} \rho\left(\mathbf{r}_{\mathrm{b}}\right)$ & $H\left(\mathbf{r}_{\mathrm{b}}\right)$ \\
\hline $\mathrm{H}_{2} \mathrm{CSe}$...SeCH $\mathrm{SH}_{2}$ & 0.0109 & 0.0349 & 0.0010 \\
\hline $\mathrm{F}_{2} \mathrm{CSe} \cdots \mathrm{SeCH}_{2}$ & 0.0099 & 0.0326 & 0.0011 \\
\hline $\mathrm{Cl}_{2} \mathrm{CSe} \ldots . . \mathrm{SeCH}_{2}$ & 0.0102 & 0.0327 & 0.0010 \\
\hline $\mathrm{Br}_{2} \mathrm{CSe} \cdots \mathrm{SeCH}{ }_{2}$ & 0.0106 & 0.0339 & 0.0010 \\
\hline$(\mathrm{OH})_{2} \mathrm{CSe} \cdots \mathrm{SeCH}_{2}$ & 0.0101 & 0.0328 & 0.0011 \\
\hline$\left(\mathrm{CH}_{3}\right)_{2} \mathrm{CSe} \cdots \cdot \mathrm{SeCH}_{2}$ & 0.0101 & 0.0321 & 0.0010 \\
\hline $\mathrm{F}_{2} \mathrm{CSe}_{\ldots} \ldots \mathrm{SeCF}_{2}$ & 0.0079 & 0.0271 & 0.0011 \\
\hline $\mathrm{Cl}_{2} \mathrm{CSe} \cdots \mathrm{SeCCl}{ }_{2}$ & 0.0100 & 0.0324 & 0.0011 \\
\hline $\mathrm{Br}_{2} \mathrm{CSe} \cdots \mathrm{SeCBr}_{2}$ & 0.0121 & 0.0380 & 0.0009 \\
\hline$(\mathrm{OH})_{2} \mathrm{CSe} \cdots \mathrm{SeC}(\mathrm{OH})_{2}$ & 0.0079 & 0.0268 & 0.0011 \\
\hline$\left(\mathrm{CH}_{3}\right)_{2} \mathrm{CSe} \cdots \mathrm{SeC}\left(\mathrm{CH}_{3}\right)_{2}$ & 0.0099 & 0.0317 & 0.0010 \\
\hline
\end{tabular}

[a] $\rho\left(\mathbf{r}_{\mathrm{b}}\right)$ : electron density. $\nabla^{2} \rho\left(\mathbf{r}_{\mathrm{b}}\right)$ : Laplacian of the electron density. $H\left(\mathbf{r}_{\mathbf{b}}\right)$ : total electronic energy density. All values in au. firms that there is a bonding interaction between these atoms. The electron densities, which range from 0.0100 to $0.0121 \mathrm{au}$, and $\nabla^{2} \rho\left(\mathbf{r}_{\mathrm{b}}\right)$ values, which range from 0.0271 to $0.0380 \mathrm{au}$, are similar to the values reported for other YB interactions. ${ }^{[11,47]}$ The small and positive values of $\rho\left(\mathbf{r}_{\mathrm{b}}\right), \nabla^{2} \rho\left(\mathbf{r}_{\mathrm{b}}\right)$, and $H\left(\mathbf{r}_{\mathrm{b}}\right)$ are typical of closed-shell interactions.

The representation of the negative gradient of molecular electrostatic potential $-\nabla V(\mathbf{r})$ [i.e. the electric field $E(\mathbf{r})$ ] indicates the direction of the Coulombic forces acting on $\mathbf{r}^{[48]}$ Figure $3 \mathrm{a}$ shows the electric field lines (EFLs) of the $\mathrm{H}_{2} \mathrm{CSe} \cdots \mathrm{SeCH}_{2}$ complex. Looking at the EFLs at the intermolecular region reveals that the electrostatic forces are directed towards the nuclei of the selenium atoms. Moreover, some of the EFLs that emanate from the local minima of the topology of $V(r)$ (lone pairs of the Se atoms) and head towards the nucleus of the other selenium atom $\left[V_{s, \min }(\mathrm{Se} 2) \rightarrow \operatorname{Nucleus}(\mathrm{Se} 1)\right]$. According to QTAIM the atomic basins of the selenium atoms are divided by a interatomic surface (IAS), indicated by a solid black line in Figure $3 \mathrm{a}$. The topology of $V(\mathbf{r})$ shows that the basin of Se2 is completely enclosed by a zero-flux surface and the EFLs indicate that there are two regions of high electron density belonging to the $\mathrm{Se} 2$ atom that feel the attraction of the nucleus of the other selenium atom (Se1). These regions are defined as the electrostatic attraction region (EAR). ${ }^{[49]}$ Due to the symmetry of the system, all previous discussion is valid for the plane perpendicular to that in Figure $3 \mathrm{a}$, but in the opposite direction. In other words, the two lone pairs of a selenium atom feel the attraction of the nucleus of the other selenium atom and vice versa.

The $L(\boldsymbol{r})$ function is a powerful tool for the study of acidbase interactions, especially when the electrostatic component plays a minor role. ${ }^{[20]}$ Figure $3 \mathrm{~b}$ shows the envelope graph at $L(\mathbf{r})=0 \mathrm{au}$ for the $\mathrm{H}_{2} \mathrm{CSe}$...SeCH $\mathrm{Se}_{2}$ complex. The regions with high electronic charge concentration [lump-L(r) $>0$ ] of the Se atoms are in orthogonal planes. In this way, four hole-lump interactions overcome the unfavorable lump-lump and holehole interactions. It appears that multiple hole-lump interactions are the driving forces of type III Se...Se contacts. These

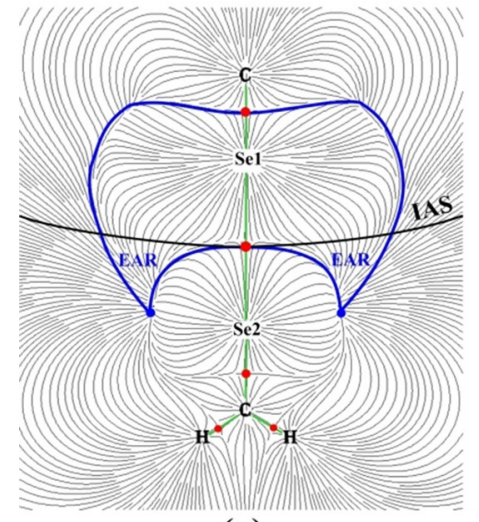

(a)

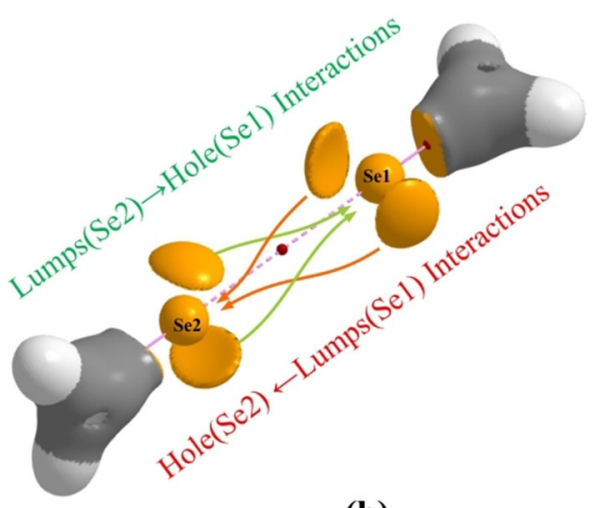

(b)

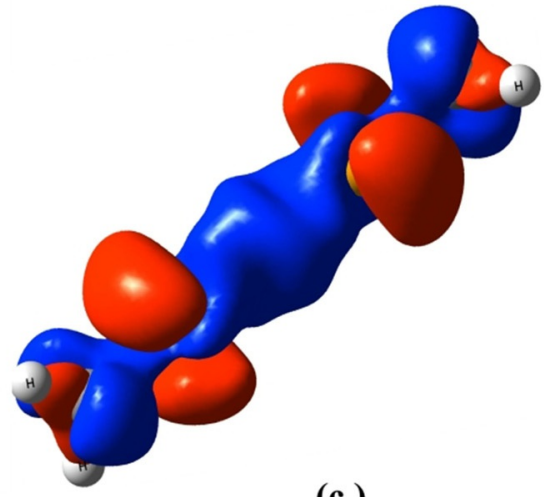

(c)

Figure 3. a) EFLs in the plane of a $\mathrm{H} 2 \mathrm{CSe}$ molecule of the $\mathrm{H}_{2} \mathrm{CSe}$...SeCH $\mathrm{H}_{2}$ complex. The bond critical points of $V(r)$ are shown (red dots). b) Envelope at $L(r)=0$ au. Note that the molecules are oriented so that the hole in the valence-shell charge concentration (VSCC) of a selenium atom is aligned with the hole in the VSCC of the other selenium atom. c) Electron density shifts for $\mathrm{H}_{2} \mathrm{CSe}$... SeCH $\mathrm{CH}_{2}$ complex at the \pm 0.0001 au isosurface. Red and blue regions indicate decreased and increased electron densities, respectively. 
multiple simultaneous interactions are consistent with earlier studies performed on other molecular interactions. ${ }^{[20,30,31]}$

The electron-density shifts that accompany formation of the $\mathrm{H}_{2} \mathrm{CSe}$... SeCH $\mathrm{S}_{2}$ complex were calculated, and the results are illustrated in Figure $3 \mathrm{c}$. Blue regions represent the accumulation of additional electron density as a result of the formation of the complex, and red regions indicate loss of electron density. An increment of the electron density in the intermolecular region (blue surface) and a decrease on the lone pairs of the Se atoms (red surface) are observed. In other words, the lone pairs of each Se atoms transfer charge to the intermolecular region, which is attracted by both selenium nuclei. It is logical to assume that the transferred electron density is channeled through the EFL. This is probably the main reason why transferred electronic charge of the lone pairs from each Se atom is mainly accumulated in the intermolecular region.

Normally, the charge transfer is attributed to interaction between the molecular orbitals corresponding to the lone pair of an heteroatom and the antibonding orbitals involving the atom with the $\sigma$ hole. ${ }^{[50]}$ However, the boundary between polarization (intrinsic component of the electrostatic interaction) and charge transfer is not well defined. ${ }^{[50-53]}$

Selected donor-acceptor orbital interactions and their second-order perturbation energies calculated by the NBO method are reported in Table 4. In complexes with $D_{2 d}$ symmetry only the charge transfer from monomer-1 toward monomer-2 is presented, since in these systems the $\mathrm{LP}(1) \mathrm{Se} 1 \rightarrow$ $\sigma^{*}(\mathrm{C}-\mathrm{Se} 2)$ and $\mathrm{LP}(2) \mathrm{Se} 1 \rightarrow \pi^{*}(\mathrm{C}-\mathrm{Se} 2)$ interactions are equivalent to $\mathrm{LP}(1) \mathrm{Se} 2 \rightarrow \sigma^{*}(\mathrm{C}-\mathrm{Se} 1)$ and $\mathrm{LP}(2) \mathrm{Se} 2 \rightarrow \pi^{*}(\mathrm{C}-\mathrm{Se} 1)$, respectively. NBO analysis shows that charge transfer occurs in both directions, from the two lone pairs of a selenium atom to the antibonding orbitals of the other monomers and vice versa. In ad-

\begin{tabular}{|lccccccc|}
\hline $\begin{array}{l}\text { Table 4. NBO analysis for studied complexes, occupation numbers of se- } \\
\text { lected molecular orbitals, and second-order }\end{array}$ perturbation energies $E^{(2)}$ \\
(donor $\rightarrow$ acceptor) ${ }^{[2]}$
\end{tabular}

[a] Energies in $\mathrm{kJ} \mathrm{mol}^{-1}$ and occupation numbers in electrons. dition, electron transfer from the LP(1)Se1 to the $\sigma^{*}(\mathrm{C}-\mathrm{Se} 2)$ orbital is greater than that from the $\operatorname{LP}(2) \mathrm{Se} 1$ to the $\pi^{*}(\mathrm{C}-\mathrm{Se} 2)$ orbital. Figure 4 shows simultaneous orbital interactions of the lone pairs of a Se atom with the unoccupied antibonding orbitals of the other monomer. It appears that these orbital overlaps play an important role in determining the geometry of these complexes.
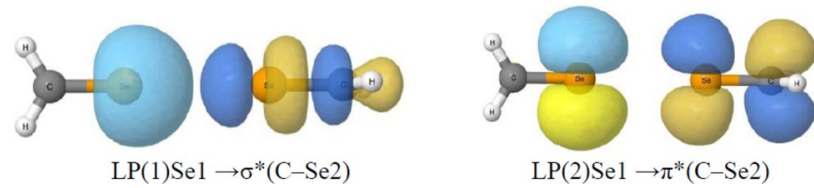

Figure 4. Orbital interactions between occupied and unoccupied antibonding orbitals of the $\mathrm{H}_{2} \mathrm{CSe}$... SeCH $\mathrm{H}_{2}$ complex.

On the other hand, systems stabilized mainly by the dispersive forces such as the dimer of methane or noble gas species are usually not classified as Lewis acid-base complexes. ${ }^{[54]}$ However, in these particular Se...Se contacts, in which the main attractive component is dispersion, significant magnitudes of electron transfers are observed. According to Grabowski et al. ${ }^{[54]}$ the electron charge transfer, if it is not negligible, is a signature of Lewis acid-base interactions. It appears to be that in these complexes both monomers simultaneously acts as Lewis acid and base.

\section{Conclusions}

We have investigated the nature of a particular type of intermolecular interactions established between two selenocarbonyl molecules. Theoretical calculations show that stable complexes with linear structures $\mathrm{C}=\mathrm{Se} . . . \mathrm{Se}=\mathrm{C}$ are formed, although both selenium atoms have a positive $\sigma$-hole at the extension of the $\mathrm{C}=\mathrm{Se}$ bond. The LMOEDA scheme reveals that the dispersive forces play a key role in stabilizing these complexes. In addition, it is also observed that the electrostatic components $E_{\text {elect }}$ and $E_{\text {pol }}$ are stabilizing, although two positive $\sigma$-holes face one another. The joint analysis of the electric field lines, the $L(\mathbf{r})=-\nabla^{2} \rho(\mathbf{r})$ function, electron-density shift, and NBO analysis reveal that these particular Se...Se contacts can be considered to be quadruple Lewis acid-base interactions. Finally, a new class of chalcogen...chalcogen contacts has been reported in this study, which we name type III $\left(\theta_{1} \approx \theta_{2} \approx 180^{\circ}\right)$.

\section{Acknowledgements}

G.J.B., D.J.R.D., and N.M.P. acknowledge SEGCYT-UNNE and CONICET for financial support. I.A. thanks the financial support from the Spanish Ministerio de Economía y Competitividad (Project No. CTQ2015-63997-C2-2-P) and Comunidad Autónoma de Madrid (Project FOTOCARBON, ref. S2013/MIT-2841). The authors also acknowledge the use of CPUs from the CECONEA. N.M.P. is a career research of CONICET, Argentina. 


\section{Conflict of interest}

The authors declare no conflict of interest.

Keywords: ab initio calculations - Lewis acids - Lewis bases · noncovalent interactions $\cdot$ selenium

[1] W. Wang, B. Ji, Y. Zhang, J. Phys. Chem. A 2009, 113, 8132-8135

[2] U. Adhikari, S. Scheiner, J. Phys. Chem. A 2014, 118, 3183-3192.

[3] E. Alikhani, F. Fuster, B. Madebene, S. J. Grabowski, Phys. Chem. Chem Phys. 2014, 16, 2430-2442.

[4] I. S. Antonijević, G. V. Janjić, M. K. Milčić, S. D. Zarić, Cryst. Growth Des. 2016, 16, 632-639.

[5] L. M. Azofra, I. Alkorta, S. Scheiner, Theor. Chem. Acc. 2014, 133, 1586.

[6] M. E. Brezgunova, J. Lieffrig, E. Aubert, S. Dahaoui, P. Fertey, S. Lebègue, J. G. Ángyán, M. Fourmigué, E. Espinosa, Cryst. Growth Des. 2013, 13, $3283-3289$.

[7] K. M. Brown, J. R. Arthur, Public Health Nutr. 2001, 4, 593-599.

[8] U. Adhikari, S. Scheiner, Chem. Phys. Lett. 2011, 514, 36-39.

[9] R. Shukla, D. Chopra, J. Phys. Chem. B 2015, 119, 14857-14870.

[10] R. Shukla, D. Chopra, J. Chem. Sci. 2016, 128, 1589-1596.

[11] X. Guo, X. An, Q. Li, J. Phys. Chem. A 2015, 119, 3518-3527.

[12] X. Guo, Q. Li, J. Mol. Model. 2015, 21, 157.

[13] Q. Zhao, D. Feng, Y. Sun, J. Hao, Z. Cai, Int. J. Quantum Chem. 2011, 111, $3881-3887$.

[14] R. Shukla, D. Chopra, Cryst. Growth Des. 2016, 16, 6734-6742.

[15] N. Ramasubbu, R. Parthasarathy, P. Murray-Rust, J. Am. Chem. Soc. 1986, $108,4308-4314$.

[16] Y. Zhang, N. Ma, W. Wang, Chem. Phys. Lett. 2012, 532, 27-30.

[17] K. E. Riley, P. Hobza, J. Chem. Theory Comput. 2008, 4, 232-242.

[18] J. S. Murray, P. Lane, P. Politzer, Int. J. Quantum Chem. 2007, 107, 22862292.

[19] K. Eskandari, J. Mol. Model. 2012, 18, 3481 - 3487.

[20] K. Eskandari, N. Mahmoodabadi, J. Phys. Chem. A 2013, 117, 13018 13024.

[21] I. Alkorta, J. Elguero, J. E. Del Bene, J. Phys. Chem. A 2013, 117, 4981 4987.

[22] K. Eskandari, H. Zariny, Chem. Phys. Lett. 2010, 492, 9-13.

[23] D. J. R. Duarte, G. L. Sosa, N. M. Peruchena, I. Alkorta, Phys. Chem. Chem. Phys. 2016, 18, 7300-7309.

[24] D. J. R. Duarte, M. S. Miranda, J. C. G. E. da Silva, J. F. Liebman, Struct. Chem. 2016, 27, 1743-1751.

[25] R. F.W. Bader, Atoms in Molecules. A Quantum Theory, Clarendon, Oxford, 1990

[26] P. L. A. Popelier, Atoms in Molecules. An Introduction, Prentice-Hall, Manchester, 2000

[27] Chemical Applications of Atomic and Molecular Electrostatic Potentials (Eds.: P. Politzer, D. Truhlar), Plenum Press, New York, 1981.

[28] P. Politzer, J. S. Murray, T. Clark, Phys. Chem. Chem. Phys. 2013, 15, $11178-11189$

[29] G. Naray-Szabo, G. G. Ferenczy, Chem. Rev. 1995, 95, 829-847.

[30] D. J. R. Duarte, N. M. Peruchena, I. Alkorta, J. Phys. Chem. A 2015, 119, $3746-3752$.

[31] J. E. Del Bene, I. Alkorta, G. Sanchez-Sanz, J. Elguero, Chem. Phys. Lett. 2011, 512, 184-187.
[32] J. E. Del Bene, G. Sanchez-Sanz, I. Alkorta, J. Elguero, Chem. Phys. Lett. 2012, 538, 14-18.

[33] J. E. Del Bene, I. Alkorta, G. Sanchez-Sanz, J. Elguero, J. Phys. Chem. A 2012, 116, 3056-3060.

[34] C. Møller, M. S. Plesset, Phys. Rev. 1934, 46, 618-622.

[35] Gaussian 09 (Revision A.01), M. J. Frisch, G. W. Trucks, H. B. Schlegel, G. E. Scuseria, M. A. Robb, J. R. Cheeseman, G. Scalmani, V. Barone, B. Mennucci, G. A. Petersson, H. Nakatsuji, M. Caricato, X. Li, H. P. Hratchian, A. F. Izmaylov, J. Bloino, G. Zheng, J. L. Sonnenberg, M. Hada, M. Ehara, K. Toyota, R. Fukuda, J. Hasegawa, M. Ishida, T. Nakajima, Y. Honda, O. Kitao, H. Nakai, T. Vreven, J. A. Montgomery, Jr., J. E. Peralta, F. Ogliaro, M. Bearpark, J. J. Heyd, E. Brothers, K. N. Kudin, V. N. Staroverov R. Kobayashi, J. Normand, K. Raghavachari, A. Rendell, J. C. Burant, S. S. lyengar, J. Tomasi, M. Cossi, N. Rega, J. M. Millam, M. Klene, J. E. Knox, J. B. Cross, V. Bakken, C. Adamo, J. Jaramillo, R. Gomperts, R. E. Stratmann, O. Yazyev, A. J. Austin, R. Cammi, C. Pomelli, J. W. Ochterski, R. L. Martin, K. Morokuma, V. G. Zakrzewski, G. A. Voth, P. Salvador, J. J. Dannenberg, S. Dapprich, A. D. Daniels, O. Farkas, J. B. Foresman, J. V. Ortiz, J. Cioslowski, D. J. Fox, Gaussian, Inc., Wallingford, CT, 2009.

[36] A. Halkier, T. Helgaker, P. Jørgensen, W. Klopper, J. Olsen, Chem. Phys. Lett. 1999, 302, 437-446.

[37] A. Halkier, W. Klopper, T. Helgaker, P. Jørgensen, P. R. Taylor, J. Chem Phys. 1999, 111, 9157-9167.

[38] P. Jurecka, J. Sponer, J. Cerný, P. Hobza, Phys. Chem. Chem. Phys. 2006 8, 1985-1993.

[39] P. Su, H. Li, J. Chem. Phys. 2009, 131, 014102.

[40] M. W. Schmidt, K. K. Baldridge, J. A. Boatz, S. T. Elbert, M. S. Gordon, J. H. Jensen, S. Koseki, N. Matsunaga, K. A. Nguyen, S. Su, T. L. Windus, M. Dupuis, J. A. Montgomery, J. Comput. Chem. 1993, 14, 1347-1363.

[41] R. J. Matta, C. F. Boyd, The Quantum Theory of Atoms in Molecules: From Solid State to DNA and Drug Design, Wiley-VCH, Weinheim, 2007.

[42] T. A. Keith, AIMAll (Version 11.12.19); TK Gristmill Software, Overland Park KS, 2011; http://aim.tkgristmill.com.

[43] T. Lu, F. Chen, J. Comput. Chem. 2012, 33, 580-592.

[44] J. (Version 14. 4), an open-source J. viewer for chemical structures in 3D. http://www.jmol.org/.

[45] A. Bondi, J. Phys. Chem. 1964, 68, $441-451$.

[46] C. Bleiholder, D. B. Werz, H. Köppel, R. Gleiter, J. Am. Chem. Soc. 2006, 128, 2666-2674.

[47] M. D. Esrafili, F. Mohammadian-Sabet, J. Mol. Model. 2015, 21, 65.

[48] N. Bouhmaida, M. Dutheil, N. E. Ghermani, P. Becker, J. Chem. Phys. 2002, 116, 6196-6204.

[49] I. Mata, E. Molins, I. Alkorta, E. Espinosa, J. Phys. Chem. A 2015, 119, $183-194$.

[50] A. E. Reed, L. A. Curtiss, F. Weinhold, Chem. Rev. 1988, 88, 899-926.

[51] M. J. S. Phipps, T. Fox, C. S. Tautermann, C.-K. Skylaris, Chem. Soc. Rev. 2015, 44, 3177-3211.

[52] W. A. Sokalski, S. M. Roszak, J. Mol. Struct. THEOCHEM 1991, 234, $387-$ 400.

[53] J. Chen, T. J. Martínez, Chem. Phys. Lett. 2007, 438, 315-320.

[54] Practical Aspects of Computational Chemistry IV (Eds.: J. Leszczynski, M. K. Shukla), Springer, New York, 2016.

Manuscript received: June 20, 2017

Revised manuscript received: August 25, 2017

Accepted manuscript online: August 29, 2017

Version of record online: October 12, 2017 